\title{
Orthosiphon stamineus leaf extract protects against ethanol-induced gastropathy in rats.
}

\begin{abstract}
Orthosiphon stamineus Benth., which is used as a gastroprotective herbal remedy in Malaysia, was assessed for its anti-ulcerogenic activity against ethanol-induced ulcers in rats. Fifty percent methanol was used to extract the oven-dried O. stamineus leaves. The extract was then lyophilized with a rotary evaporator and freeze-dried. Oral administration of $\mathrm{O}$. stamineus methanolic extract (OSME) $(125,250,500$, and $1,000 \mathrm{mg} / \mathrm{kg})$ was found to significantly decrease the ulcer index $(\mathrm{P}<.01, \mathrm{P}<.001, \mathrm{P}<.001$, and $\mathrm{P}<.001$, respectively). Histological study of a section of the rat stomach also showed a marked improvement in the gastric mucosal damage in groups receiving OSME. In order to further investigate the gastroprotective mechanism of OSME, mucus secretion and lipid peroxidation level were estimated in vitro and ex vivo. OSME exhibited dose-dependent stimulation of mucus secretion $(\mathrm{r}=0.718, \mathrm{P}<.001)$ and inhibition of lipid peroxidation in rat gastric mucosal homogenates (both in vitro $[\mathrm{r}=0.819, \mathrm{P}<.05]$ and ex vivo $[\mathrm{r}=0.981, \mathrm{P}<.05]$ ). It was concluded that the gastroprotective mechanism of OSME was partly due to its ability to inhibit lipid peroxidation and stimulate gastric mucus secretion.
\end{abstract}

Keyword: Gastroprotection; High-performance liquid chromatography profile; Lipid peroxidation; Orthosiphon stamineus. 